\title{
A DISCIPLINA PROJETOS 3 E APRENDIZAGEM ATIVA NO CURSO DE ENGENHARIA DE ENERGIA DA UNIVERSIDADE FEDERAL DO RIO GRANDE DO SUL
}

\author{
Semana Online Científica de Engenharia, 1a edição, de 25/10/2021 a 27/10/2021
}

ISBN dos Anais: 978-65-81152-19-2

\begin{abstract}
RAMIRES; Simone ${ }^{1}$
\end{abstract}
\section{RESUMO}

A disciplina Projetos 3 do Curso de Engenharia de Energia da Universidade Federal do Rio Grande do Sul, UFRGS, Porto Alegra, RS tem como objetivo incentivar a melhoria contínua e a inovação do ensino de engenharia, através do desenvolvimento de práticas inovadoras de ensino como a aprendizagem ativa. Esta alicerçado na necessidade de aperfeiçoar a formação dos acadêmicos da Escola de Engenharia da UFRGS e a sua profissionalização, diante dos desafios e oportunidades que estão se abrindo em todos os campos de conhecimento e, ainda abrigar um conjunto de projetos e atividades de diversa modalidade relacionadas com as necessidades atuais, como por exemplo, estar atento para as mudanças tecnológicas e pronto para desafios. Ainda, propõe soluções de problemas no quarteirão da Escola de Engenharia - QEE, como por exemplo, segurança, geração de energia, áreas verdes, iluminação, entre outros, possibilitando, desta forma inferir pontos que necessitam de atenção. Sendo assim, o grupo em questão, propôs um espaço de revitalização dentro do QEE/UFRGS. O projeto toma como base a integração dos pilares econômico, ambiental e social para criar um local agradável de convivência e conscientização dos acadêmicos, propondo a integração harmônica e sustentável do meio ambiente e tecnologia.De acordo Maseto (2000) a aprendizagem ativa é mais adequada para o trabalho em sala de aula, pois aposta no aluno como protagonista no processo de ensino. Ainda, a aprendizagem ativa é realizada por diferentes metodologias, como o PBL (Problem Based Learning), o PLE (Project Led Education) e o Project Work. A disciplina possibilita solucionar a lacuna entre o conhecimento teórico isolado aplicado no modelo de ensino atual e a necessidade do aluno de obter um modelo mais prático onde o conhecimento específico se encaixa em uma sequência lógica de forma a desenvolver a solução de problema real surge a importância da interdisciplinaridade.

PALAVRAS-CHAVE: Aprendizagem ativa, Sustentabilidade, Engenharia 